\title{
Anticoagulation in patients with cardiac manifestations of Chagas disease and cardioembolic ischemic stroke
}

\author{
Anticoagulação nas manifestações cardíacas da doença de Chagas e acidente vascular \\ cerebral isquêmico cardioembólico
}

Jean M.C. Monteiro', Daniel L. San-Martin'1, Beatriz C.G. Silva¹, Pedro A.P. de Jesus ${ }^{1,2}$, Jamary Oliveira-Filho ${ }^{1,2}$

\begin{abstract}
Objectives: To describe anticoagulation characteristics in patients with cardiac complications from Chagas disease and compare participants with and without cardioembolic ischemic stroke (CIS). Methods: A retrospective cohort of patients with Chagas disease, using anticoagulation, conducted from January 2011 to December 2014. Results: Forty-two patients with Chagas disease who were using anticoagulation were studied (age 62.9 12.4 years), 59.5\% female and 47.6\% with previous CIS, 78.6\% with non-valvular atrial fibrillation and $69.7 \%$ with dilated cardiomyopathy. Warfarin was used in $78.6 \%$ of patients and dabigatran (at different times) in $38 \%$. In the warfarin group, those with CIS had more medical appointments per person-years of follow-up (11.7 vs 7.9), a higher proportion of international normalized ratios within the therapeutic range ( $57 \%$ vs $42 \%$ medical appointments, $p=0.025)$ and an eight times higher frequency of minor bleeding (0.64 vs 0.07 medical appointments). Conclusion: Patients with Chagas disease and previous CIS had better control of INR with a higher frequency of minor bleeding.
\end{abstract}

Keywords: Chagas disease; warfarin; stroke; atrial fibrillation.

RESUMO

Objetivos: descrever as características da anticoagulação em pacientes com manifestações cardíacas da doença de Chagas (MCDC) e comparar os participantes com sem acidente vascular cerebral isquêmico cardioembólico (AVC IC . Resultados: 42 pacientes com MCDC em anticoagulação foram estudados (62,9 \pm 12,4 anos), 59,5\% do sexo feminino e 47,6\% com AVC prévio, 78,6\% portadores de fibrilação atrial não valvar e 69,7\% com cardiomiopatia dilatada. Varfarina foi utilizada em 78,6\% dos pacientes e dabigatrana em $38 \%$ (em momentos diferentes). No grupo da varfarina, aqueles com AVC (11,7 vs 7,9), maior taxa de RNI na faixa terapêutica ( $57 \%$ vs $42 \%$ consultas médicas, $p=0,025$ ) e uma frequência oito vezes maior de

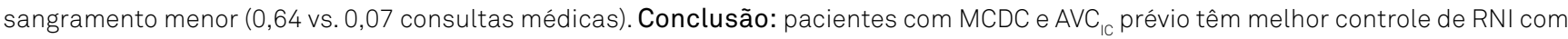
maior frequência de sangramento menor.

Palavras-chave: doença de Chagas; varfarina; acidente vascular cerebral; fibrilação atrial.

Chagas disease affects approximately 17 million people in Latin America, making it a public health problem in this region ${ }^{1}$. It is the main cause of cardiomyopathy in South America $^{1,2}$ and the major cause of non-ischemic cardiomyopathy in Brazil. This infection, caused by the protozoan parasite Trypanosoma cruzi, is a significant cause of illness and premature death ${ }^{3}$ and has been associated as a cause of cerebrovascular disease in several studies ${ }^{4,5,6,7,8}$.
Anticoagulants are frequently used to prevent embolic events in patients at a high risk of embolism ${ }^{9}$. The standard drug, warfarin, has interactions with many drugs and requires an exhaustive control of the international normalized ratio (INR), and the risk of bleeding is significant ${ }^{10,11}$.

There is a lack of data on patients with Chagas disease who use anticoagulation drugs. This study aims to describe anticoagulation characteristics, embolic event rates and

${ }^{1}$ Universidade Federal da Bahia, Faculdade de Medicina, Salvador BA, Brasil;

${ }^{2}$ Universidade Federal da Bahia, Complexo Hospitalar Professor Edgard Santos, Salvador BA, Brasil.

Correspondence: Jean Michell Correia Monteiro; Rua Waldemar Falcão, 1654; 40296-700 Salvador BA, Brasil; E-mail: jk_michell@hotmail.com Conflict of interest: There is no conflict of interest to declare.

Support: We thank the support of the Neurology Academic League of Federal University of Bahia (LAN - FMB).

Received 19 June 2017; Received in final form 09 October 2017; Accepted 23 October 2017. 
side effects in patients with cardiac manifestations of Chagas disease and to compare groups with or without a prior embolic event.

\section{METHODS}

A retrospective cohort study involving patients followed at the outpatient anticoagulation clinic of the Complexo Hospitalar Universitário Professor Edgard Santos in Salvador, Brazil. Data was obtained from medical records from January 2011 to December 2014. Patients were referred to this specialized service through the Public Health System network.

Inclusion criteria were participants with Chagas disease who were using oral anticoagulation, either warfarin or dabigatran etexilate. Their serological tests for Chagas disease was confirmed with ELISA/hemaglutination. The Chagas disease cardiac manifestation diagnoses were considered either as an arrhythmic form (atrioventricular block, need for pacemaker, ventricular tachycardia, atrial fibrillation or atrial flutter) or a dilated cardiomyopathy form, defined by an ejection fraction less than $40 \%$; or between $41 \%$ and $49 \%$ with increased left ventricle dimensions on echocardiography or cardiac magnetic resonance imaging. Exclusion criteria were participants with less than three follow-up medical appointments, follow-up in other medical services for anticoagulation and absence of data for monitoring participants' anticoagulation.

The INR therapeutic range was defined as a value between 2.0 and 3.0. Inadequate adherence was defined as medical appointments in which medical prescription of anticoagulants was not used properly. Interruptions: drug discontinuation for any reason. Major bleeding: fatal or symptomatic intracranial bleeding, transfusion or surgical intervention requirements. Gingival and genital bleeding, increased menstrual flow or spontaneous hematoma that did not require transfusion or surgical intervention were considered to be minor bleeding ${ }^{12}$.

This study was approved by the Research Ethics Committee of the School of Medicine of the Federal University of Bahia (Statement 856 694).

\section{Statistical analysis}

A longitudinal analysis was performed between groups, considering patients with or without prior cardioembolic ischemic stroke (CIS) who were using warfarin, and the results reported in person-years. Patients were censored in the last available record. The number of medical appointments per person-years of follow-up was calculated for each group, as well as the INR being out of range, drug dose change and bleeding. The Student's t test or Mann-Whitney U test were used to compare continuous variables and Fisher's exact test was used for categorical variables when appropriate. The number of medical appointments per year was calculated for each of the characteristics studied. Results were described as mean \pm standard deviation, median [interquartile range] or proportion (\%). The $\mathrm{p}$ value was shown to help data description. The statistical analysis was performed with SPSS version 21.

\section{RESULTS}

This study included 42 patients with a mean age of 62.9 years $( \pm 12.4), 59.5 \%$ being female $(n=25)$, from a sample of 123 patients with Chagas disease. Table 1 shows the participants' sociodemographic characteristics and comorbidities. The two most frequent comorbidities were systemic arterial hypertension, present in $85.7 \%(n=36)$ and nonvalvular atrial fibrillation (83.3\%). The dilated cardiomyopathy form was present in $69.7 \%$ of the sample, the arrhythmic form in $85.7 \%$ and both forms in $64.3 \%$. Ischemic stroke occurred in $47.6 \%(n=20)$, and all of them were deemed cardioembolic. No arterial sources of emboli were found on either carotid duplex or angiographic studies (computed tomography angiography, magnetic resonance angiography or digital subtraction angiography).

Warfarin use was reported in 33 patients. Nine patients used only dabigatran etexilate during the study period and $16(38 \%)$ patients used it at some stage during the follow-up period. The median period of follow-up for dabigatran etexilate was 1.22 years [0.36-1.86]. There was only one report of minor bleeding in the group of dabigatran etexilate use, and one in the group that used warfarin. The medical appointments for patients using warfarin were 9.7 per person-year in the follow-up and 3.8 in the dabigatran etexilate group. The

Table 1. Sociodemographic characteristics and comorbidities of the sample $(n=42)$.

\begin{tabular}{|c|c|}
\hline Characteristics & Values \\
\hline Age, mean ( \pm SD) & $62.9 \pm 12.4$ \\
\hline Female n (\%) & $25(59.5)$ \\
\hline Black race $n(\%)$ & $12(28.5)$ \\
\hline Hypertension n (\%) & $36(85.7)$ \\
\hline Atrial fibrillation/flutter n (\%) & 35 (83.3) \\
\hline Cardiac insufficiency n (\%) & $30(71.4)$ \\
\hline Cardioembolic stroke n (\%) & $20(47.6)$ \\
\hline Coronary artery disease $n(\%)$ & $6(14.3)$ \\
\hline Diabetes mellitus type 2 n (\%) & $4(9.5)$ \\
\hline Chronic kidney disease n (\%) & $6(14.3)$ \\
\hline Dabigatran etexilate use only n (\%) & $9(21.4)$ \\
\hline $\mathrm{CHADS}_{2}$, median [interquartile range] & $3.0[2.0-4.0]$ \\
\hline $\mathrm{CHA}_{2} \mathrm{DS}_{2} \vee \mathrm{ASc}$, median [interquartile range] & $4.0[3.0-5.0]$ \\
\hline HAS-BLED, median [interquartile range] & $2.0[1.0-3.0]$ \\
\hline
\end{tabular}

HAS-BLED: Hypertension, Abnormal renal or liver function, Stroke/Transient Ischemic Attack, Bleeding or predisposition, Labile International Normalized Ratio, Age $\geq 65$, Drugs or alcohol concomitantly; CHADS2: Congestive heart failure, Hypertension, Age $\geq 75$ years, Diabetes mellitus, Stroke/transient ischemic attack; CHA2DS2VASc: Congestive heart failure, Hypertension, Age $\geq 75$ years, Diabetes mellitus, Stroke/Transient Ischemic Attack/ Thromboembolic event, Vascular disease, Age 65 to 74 years, Sex category. 
clinical characteristics of patients with or without previous CIS and warfarin use is shown in Table 2. Non-valvular atrial fibrillation or atrial flutter was considerably less frequent in patients with prior ischemic stroke (53.3 vs $94.4 \%, \mathrm{p}=0.012$ ). In the warfarin group, among common medications used in this population, statins were more common in those with a previous CIS (66.7 vs $11.1 \%, \mathrm{p}=0.001$ ) (Table 3).

Considering the warfarin group and patients with or without prior CIS, the median time of follow-up in first group was 1.4 years [1.1-3.4] and 1.8 years [0.9-3.8] in second group, $p=0.518$. The median number of medical appointments per year was much higher in patients with a prior CIS when compared to patients without a CIS (12.5 [9.2-15.2] vs 7.6 [6.8-9.5], $\mathrm{p}=0.001)$. The median frequency of an INR in the therapeutic range was higher in the CIS group $(57.1 \%$ [46.1-72.7] vs 42\% [32.8-62.8], $p=0.025)$. There was no significant difference in the median of medical appointments per year in the subgroup with or without dose changes of warfa$\operatorname{rin}(4.4$ [1.4-5.7] vs 3.5 [2.4-4.6], p = 0.620).

In the longitudinal analysis (Table 4), the rate of medical appointments remained higher in the CIS group (11.7 vs 7.9). The rate of medical appointments with temporary interruptions was similar between the groups, however patients with CIS had an eight times higher incidence of minor bleeding than those without CIS ( 0.64 vs 0.07$)$. The rate of medical appointments with a dose change was slightly more common in the CIS group (4.20 vs 3.30 ), but compliance was

Table 2. Clinical characteristics between groups in warfarin use and prior stroke.

\begin{tabular}{lccc}
\hline \multirow{2}{*}{ Characteristics } & \multicolumn{2}{c}{ Prior stroke } & p-value \\
\cline { 2 - 3 } & Yes $(\mathrm{n}=15)$ & No $(\mathrm{n}=18)$ & \\
\hline Age, mean $( \pm \mathrm{SD})$ & $65.1 \pm 11.1$ & $60.9 \pm 13.5$ & 0.469 \\
Female, $n(\%)$ & $8(53.3)$ & $12(66.7)$ & 0.493 \\
Hypertension, $\mathrm{n}(\%)$ & $14(93.3)$ & $16(88.9)$ & 1.000 \\
Heart failure, $\mathrm{n}(\%)$ & $9(66.0)$ & $15(83.3)$ & 0.239 \\
CAD, $n(\%)$ & $1(6.7)$ & $5(27.8)$ & 0.186 \\
AF/flutter, $\mathrm{n}(\%)$ & $8(53.3)$ & $17(94.4)$ & 0.012 \\
\hline
\end{tabular}

CAD: coronary artery disease; AF: non-valvular atrial fibrillation.

Table 3. Common drugs used in patients with warfarin.

\begin{tabular}{lccc}
\hline \multirow{2}{*}{ Medications } & \multicolumn{2}{c}{ Prior stroke } & \multirow{2}{*}{ p-value } \\
\cline { 2 - 3 } & Yes $(\mathrm{n}=15)$ & No $(\mathrm{n}=18)$ & \\
\hline Amiodarone, $\mathrm{n}(\%)$ & $4(26.7)$ & $3(16.7)$ & 0.674 \\
Beta-blocker, $\mathrm{n}(\%)$ & $7(46.7)$ & $12(66.7)$ & 0.304 \\
Digoxin, $\mathrm{n}(\%)$ & $1(6.7)$ & $4(22.2)$ & 0.346 \\
ARB/ACE inhibitor, $\mathrm{n}(\%)$ & $13(86.7)$ & $14(77.8)$ & 0.665 \\
Thiazide diuretics, $\mathrm{n}(\%)$ & $10(66.7)$ & $16(88.9)$ & 0.203 \\
CCB, $\mathrm{n}(\%)$ & $2(13.3)$ & $2(11.1)$ & 1.000 \\
Antidepressive, $\mathrm{n}(\%)$ & $4(26.7)$ & $3(16.7)$ & 0.674 \\
Antiseizure drugs, $\mathrm{n}(\%)$ & $4(26.7)$ & $1(5.6)$ & 0.152 \\
Statin, $\mathrm{n}(\%)$ & $10(66.7)$ & $2(11.1)$ & 0.001 \\
\hline
\end{tabular}

ARB: angiotensin receptor blockers; ACE inhibitor: angiotensin-converting enzyme inhibitor; CCB: calcium channel blocker. better (0.40 vs 0.14$)$. During the follow-up period, there was no major bleeding or embolic event. The total period of follow-up was 27.82 person-years for patients with CIS and 38.17 person-years for those without CIS.

\section{DISCUSSION}

This study describes the anticoagulation characteristics of Brazilian patients with Chagas disease and cardiac manifestations (CDCM). We investigated the medical appointments for an INR within the therapeutic range, drug changes, interruptions, inadequate adherence to treatment and as well as embolic events and the side effects in individuals who took anticoagulation drugs, comparing groups with and without CIS.

Both groups were comparable regarding the main sociodemographic and clinical characteristics. Patients who had a prior CIS and had taken warfarin had more medical appointments with dose changes, presented with an INR within the therapeutic range more frequently and had a higher rate of minor bleeding. There were no reports regarding embolic events and major bleeding during the follow-up period.

A higher number of medical appointments, a higher rate of good adherence and a therapeutic INR in the group with prior ischemic stroke may reflect better care of patients, because they had a highly morbid disease such as stroke or individual characteristics of this group. The INR being within range was less frequent in our study than in previous studies $^{11,12,13,14}$. The cause of inadequate control in a higher proportion of patients is unknown, but it could have been influenced by socioeconomic factors, nutritional factors or Chagas disease being a poor predictor of INR control.

Although in this sample there was no major bleeding during the follow-up period, the frequency of minor bleeding was approximately eight times higher in patients with a previous CIS than without a previous CIS. The number of medical appointments with drug changes was slightly more common in the CIS group and may justify this finding. In a Brazilian study with 280 patients using warfarin, of whom $30 \%(n=84)$ had

Table 4. Longitudinal analysis in warfarin patients and prior ischemic stroke.

\begin{tabular}{|c|c|c|}
\hline \multirow{3}{*}{ Characteristics } & \multirow{2}{*}{\multicolumn{2}{|c|}{$\begin{array}{c}\text { Prior stroke } \\
\text { (person-years of follow-up) } \\
\text { Rate }(\mathrm{Cl} 95 \%)\end{array}$}} \\
\hline & & \\
\hline & Yes $(n=15)$ & No $(n=18)$ \\
\hline $\begin{array}{l}\text { MA with INR in therapeutic } \\
\text { range }\end{array}$ & $7.04(6.39-7.66)$ & $3.95(3.51-4.39)$ \\
\hline $\begin{array}{l}\text { MA with temporary } \\
\text { interruptions }\end{array}$ & $0.79(0.52-1.17)$ & $0.73(0.51-1.03)$ \\
\hline $\begin{array}{l}\text { MA with minor bleeding } \\
\text { related }\end{array}$ & $0.64(0.46-0.79)$ & $0.07(0.02-0.20)$ \\
\hline MA with dose change & $4.20(3.61-4.83)$ & $3.30(2.87-3.74)$ \\
\hline MA with poor compliance & $0.14(0.05-0.36)$ & $0.40(0.24-0.65)$ \\
\hline
\end{tabular}

MA: medical appointments; INR: international normalized ratio. 
Chagas disease, there was no difference in the history between the Chagas disease group and those without this disease in the frequency of bleeding $(66.7 \% \text { vs } 70.9 \%)^{15}$. However, this population had fewer potentially severe warfarin drug interactions. In our study, it was not possible to evaluate this information. Patients with CIS have more comorbidities in general, and one possible explanation is the use in this subgroup of many drugs with potential drug interaction, although the INR frequency within the therapeutic range was more common in the CIS patients in our study. Another study prospectively evaluating 52 patients with Chagas disease and warfarin use found only one case of major bleeding (risk of $2 \%$ per year) and no embolic event during a mean follow-up of 14 months 9 .

In this study, approximately $48 \%$ of patients with Chagas disease had an ischemic stroke, all of them due to cardioembolism. This reaffirms the strong association of this disease with cerebrovascular pathologies, as already determined by previous studies ${ }^{45,6,6,7,8}$. In this sample, non-valvular atrial fibrillation was $40 \%$ less frequent in patients with CIS, probably because the most frequent indication for anticoagulation in patients without prior CIS is atrial fibrillation itself. All patients were using an anticoagulation drug for some medical reason. Nonetheless, it was not possible to evaluate if the prescriptions for anticoagulation were based on a risk model for all patients, especially for those without cardiomyopathy and an embolic event. This sample comprised only patients with CDCM, limiting any analysis regarding patients with Chagas disease but without cardiac manifestations. It has been shown that, even in patients without cardiac abnormalities, a confirmed Chagas disease positive serology increases the risk of ischemic stroke ${ }^{5,6,7}$.

This study has some limitations. We had a small sample size from a single center and the retrospective analysis and the followup period was relatively short when compared to large clinical trials published in this area of knowledge. The impossibility of standardizing treatment among patients may raise concerns about potential sources of bias. Only nine patients used dabigatran etexilate continuously throughout our study, precluding an adequate analysis of this drug in this subgroup of patients, although those who changed to dabigatran etexilate during the follow-up period showed a reduction in total medical appointments. Thus, further observational studies are necessary, especially in Latin America, to evaluate the profile of oral anticoagulant therapy in patients with Chagas disease and also to raise hypotheses about the possible efficacy of new anticoagulants in this population.

In conclusion, our results suggest that patients with Chagas disease and previous CIS required more medical appointments for anticoagulation control, had better control of INRs and a higher frequency of minor bleeding. Overall, bleeding rates were low for both warfarin and dabigatran, suggesting that these drugs can be used safely in selected patients with Chagas disease who require oral anticoagulation.

\section{References}

1. World Health Organization. Control of Chagas' disease: report of a WHO Expert Committee. World Health Organ Tech Rep Ser. 2002;905:1-92.

2. Mansur AP, Souza MFM, Favarato D, Avakian SD, César LAM, Aldiqui JM, Ramirs JAF. Stroke and ischemic heart disease mortality trends in Brazil from 1979 to 1996. Neuroepidemiology. 2003;22(3):179-83. https://doi.org/10.1159/000069893

3. Longo DL. Chagas' fisease. N Engl J Med. 2015;373(5):456-66. https://doi.org/10.1056/NEJMra1410150

4. Carod-Artal FJ, Vargas AP, Melo M, Horan TA. American trypanosomiasis (Chagas' disease): an unrecognised cause of stroke.J Neurol Neurosurg Psychiatry. 2003;74(4):516-8. https://doi.org/10.1136/jnnp.74.4.516

5. Oliveira-Filho J, Viana LC, Vieira-de-Melo R, Faiçal F, Torreão JA, Villar FA et al. Chagas disease Is an independent risk factor for stroke baseline characteristics of a Chagas disease cohort. Stroke. 2005;36(9):2015-7. https://doi.org/10.1161/01.STR.0000177866.13451.e4

6. Carod-Artal FJ, Vargas AP, Horan TA, Nunes LGN. Chagasic cardiomyopathy is independently associated with ischemic stroke in Chagas disease. Stroke. 2005;36(5):965-70. https://doi.org/10.1161/01.STR.0000163104.92943.50

7. Paixão LC, Ribeiro AL, Valacio RA, Teixeira AL. Chagas disease: independent risk factor for stroke. Stroke. 2009;40(12):3691-4. https://doi.org/10.1161/STROKEAHA.109.560854

8. Nunes MCP, Barbosa MM, Ribeiro ALP, Barbosa FB, Rocha MO. Ischemic cerebrovascular events in patients with Chagas cardiomyopathy: a prospective follow-up study. Journal of the Neurological Sciences. 2009;278(1-2):96-101. https://doi.org/10.1016/j.jns.2008.12.015
9. Sousa AS, Xavier SS, Freitas GR, Hasslocher-Moreno A. Prevention strategies of cardioembolic ischemic stroke in Chagas' disease. Arq Bras Cardiol. 2008;91(5):306-10. https://doi.org/10.1590/S0066-782X2008001700004

10. Birman-Deych E, Radford MJ, Nilasena DS, Gage BF. Use and effectiveness of warfarin in Medicare beneficiaries with atrial fibrillation. Stroke. 2006;37(4):1070-4. https://doi.org/10.1161/01.STR.0000208294.46968.a4

11. Hylek EM, Evans-Molina C, Shea C, Henault LE, Regan S. Major hemorrhage and tolerability of warfarin in the first year of therapy among elderly patients with atrial fibrillation. Circulation. 2007;115(21):2689-96. https://doi.org/10.1161/CIRCULATIONAHA.106.653048

12. Connolly SJ, Ezekowitz MD, Yusuf S, Eikelboom J, Oldgren J, Parekh A et al. Dabigatran versus Warfarin in Patients with Atrial Fibrillation. N Engl J Med. 2009;361(12):1139-51. https://doi.org/10.1056/NEJMoa0905561

13. Hori M, Connolly SJ, Zhu J, Liu LS, Lau CP, Pais P et al. Dabigatran versus Warfarin: effects on ischemic and hemorrhagic strokes and bleeding in Asians and Non-Asians with atrial fibrillation. Stroke. 2013;44(7):1891-6. https://doi.org/10.1161/STROKEAHA.113.000990

14. Eikelboom JW, Connolly SJ, Brueckmann M, Granger CB, Kappetein AP, Mack MJ et al. Dabigatran versus Warfarin in patients with mechanical heart valves. N Engl J Med. 2013;369(13):1206-14. https://doi.org/10.1056/NEJMoa1300615

15. Martins MA, Ribeiro DD, Nobre VA, Pereira FR, César CC, Rocha MO et al. Agreement among four drug information sources for the occurrence of warfarin drug interactions in Brazilian heart disease patients with a high prevalence of Trypanosomacruzi infection. Eur J Clin Pharmacol. 2013;69(4):919-28. https://doi.org/10.1007/s00228-012-1411-6 